\title{
EXERGY ANALYSIS OF THERMAL POWER PLANT (RTPP)
}

\author{
B. Yeswanth Kumar Reddy ${ }^{1}$, G. Venkata Subbaiah Yadav², S. Pavan Kumar ${ }^{3}$, M. Ashok Kumar \\ ${ }^{1}$ Lecturer, Mechanical Engineering Department, JNTUA College of Engineering, Pulivendula, AP, India \\ ${ }^{2}$ Lecturer, Mechanical Engineering Department, Chaitanya Bharathi Institute of Tech., Proddatur, AP, India \\ ${ }^{3}$ M. Tech, Mechanical Engineering Department, JNTUA College of Engineering, Pulivendula, AP, India \\ ${ }^{4}$ M. Tech, Mechanical Engineering Department, JNTUA College of Engineering, Pulivendula, AP, India
}

\begin{abstract}
The energy supply to the demand narrowing down day by day around the world, the growing demand of the power has made the ower plants of scientific interest, but most of the power plants are designed by the energetic performance criteria based on the first law of thermodynamics only. The real useful energy loss cannot be identified by the first law of thermodynamics, because it does not differentiate between the quality and quantity of energy. The project on Exergy Analysis was undertaken on Rayalaseema Thermal Power Project located in Kadapa, Andhra Pradesh. The capacity of the plant is $5 \times 210$ MW. Energy analysis presents only quantities results while Exergy analysis presents qualitative results about actual energy consumption. The main objective is to analyze the system components separately and to identify and quantify sites having largest energy and exergy efficiency losses .It also presents major losses of available energy at super-heater, boiler and turbine section. Exergy destruction and energy loss comparison charts are drawn for different components. The results are tabulated and graphs are plotted to show correlation between various parameters. This project would also throw light on the scope for further research and recommendations for improvement in the further existing plant.
\end{abstract}

Keywords: Exergy, Energy, Thermodynamics.

\section{INTRODUCTION TO R.T.P.P}

Rayalaseema thermal power project (R.T.P.P), is one of the major generation unit, developed in A.P., to meet the growing demand for power, the project envisaged the installation of $2 \times 210 \mathrm{MW}$ coal based thermal generation units under stage I. The first $210 \mathrm{MW}$ unit for commercial operation was started on 25 Nov1994 and the second unit on 30 Mar 1995 . The plant has another $2 \times 210 \mathrm{MW}$ coal based thermal generation units under stage II. In the stage 2 , the $* * *$

third Unit was started on 24 Jan 2007 and the fourth unit is under construction.

The R.T.P.P. project is located at a distance of $8 \mathrm{~km}$ from Muddunur railway station of south central railway on Chennai-Mumbai railwsay line. The site is selected at an adequate distance from the residential areas and it has an area of 2600 Acres. The water requirements for the project are met from Mylavaram reservoir across river Penna, which is $23 \mathrm{KM}$ away from the power plant.

\subsection{Layout of Thermal Power Plant}

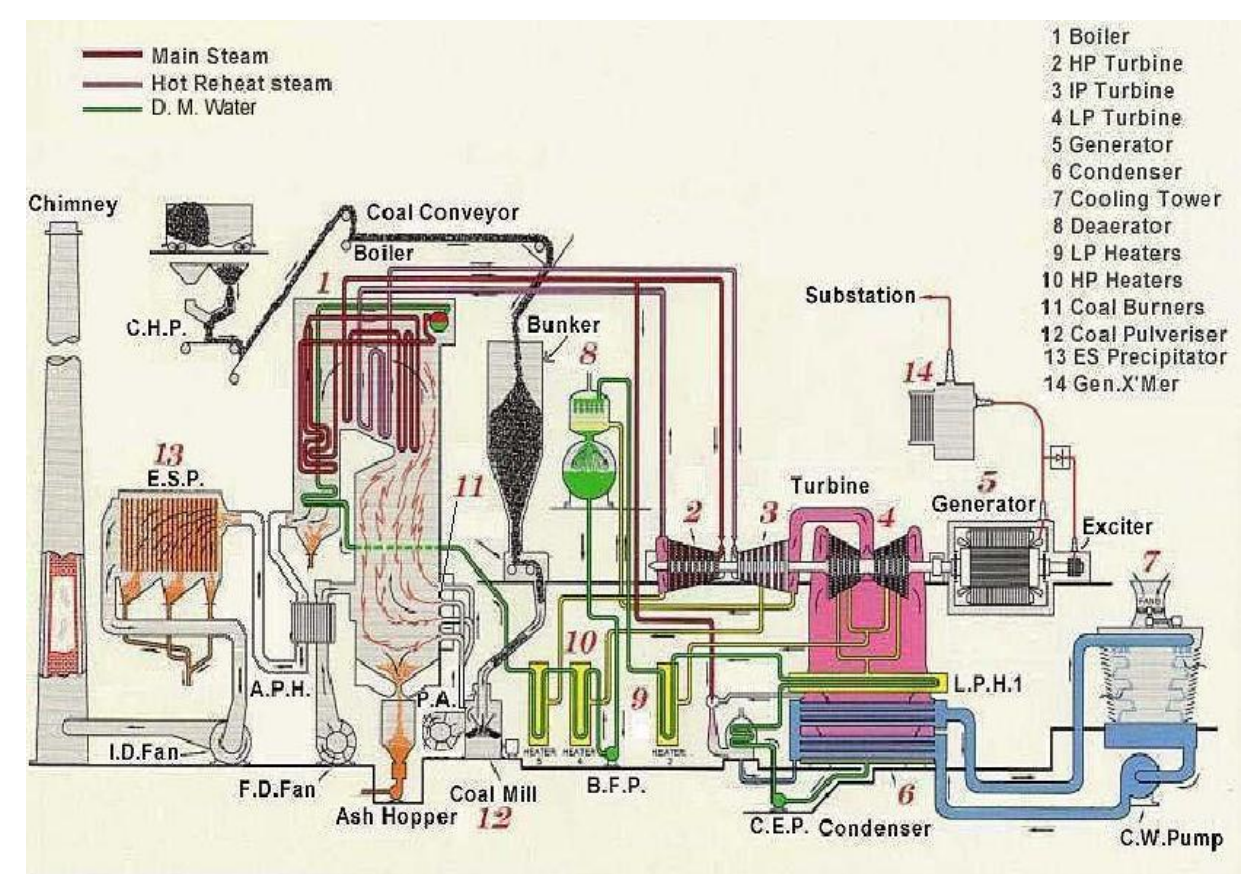

Fig-1: Layout of Thermal power plant 


\subsection{Working Cycles}

The fundamental forms of energy with which thermal stations are principally concerned are heat and work. Heat produces work and this work is further converted into electrical energy through a medium .i.e. electrical generator.

For the purpose of understanding of thermal plants, the phenomenon of thermodynamics vapor power cycles is explained here under

i. Rankine cycle

ii. Regenerative cycle

iii. Reheat cycle

\subsubsection{Rankine cycle}

Rankine cycle is theoretical cycle on which steam turbine (or engine) works.

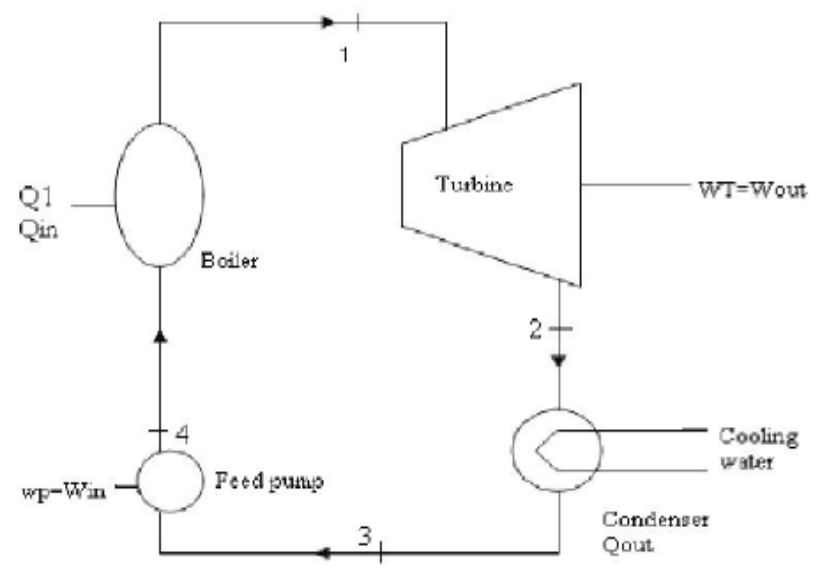

Fig 2: Rankine cycle

\subsubsection{Regenerative Cycle}

The principle of regeneration can be practically utilized by extracting steam from turbine at several locations supply it to the regenerative heater. The most advantageous condensate heating temperature is selected depending on the throttle conditions and this determines the number of heaters to be used. Figure shows the layout of condensing steam power plant in which a surface condenser is used to condense all the steam that is not extracted for feed water heating. The turbine is double extracting and boiler is equipped with a super heater.

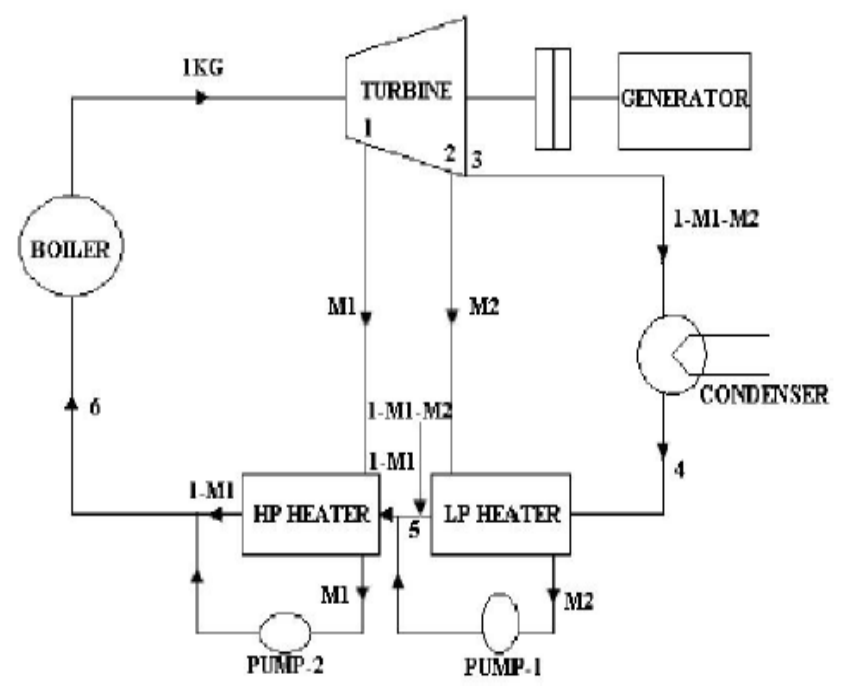

Fig-3: Regenerative cycle

\subsubsection{Reheat Cycle}

In reheat cycle the steam is extracted from a suitable point in the turbine and is reheated it with the support of flue gases and $\mathrm{m}$ in the boiler furnace. The main purpose of reheating to increase the dryness fraction of steam passing through the lower stages of the turbine.

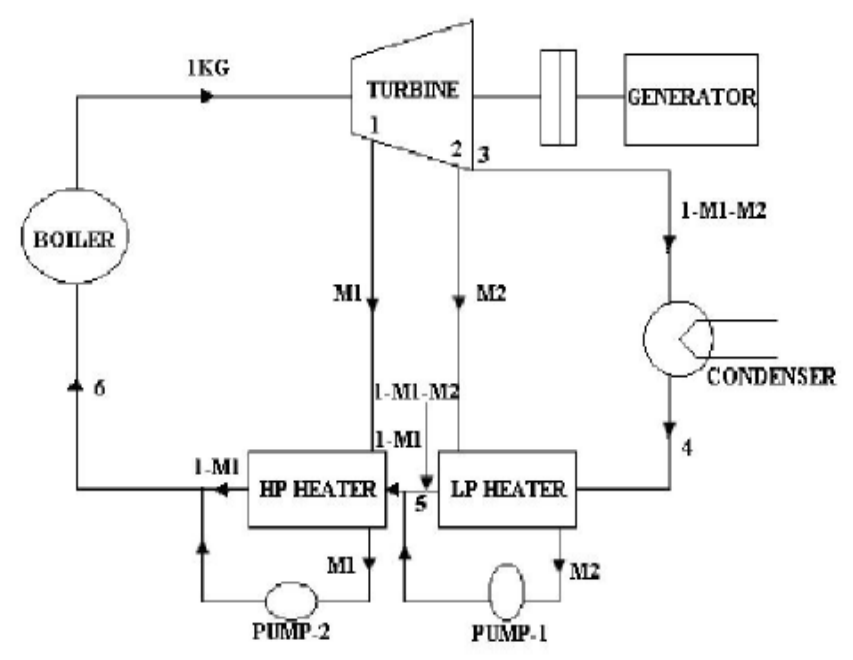

Fig-4: Reheat Cycle

\subsection{Plant Losses}

By fact the largest turbine house loss is the heat carried away in the circulating water passin However, show where the principle losses occur and enable the question of efficiency to be studied aim is to keep the losses as small as possible by good operation. To more easily understand the concept of exergy, you can consider this picture as an analogy: Likewise we can't extract paste completely from a tube we can't utilize energy completely from a source means there must be some losses during the process or a work being done and most of the losses is due to entropy which we can't avoid completely. 


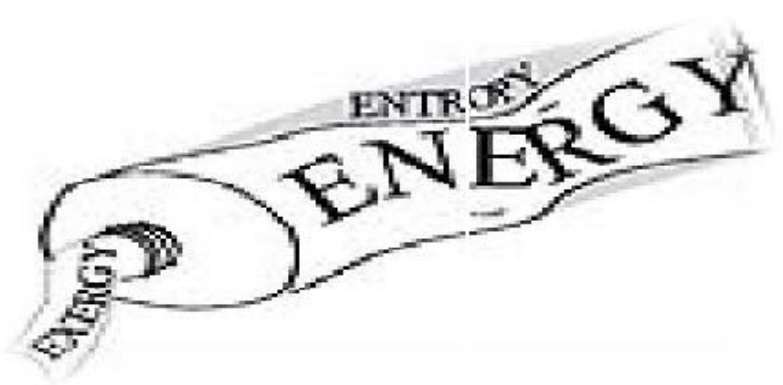

2. INTRODUCTION TO EXERGY

\subsection{Energy}

The word energy derives from the Greek term "energy" was used by THOMAS YOUNG in 1807. is a point function and a property of the system possibly appears for the first time in the work of A the 4th century. Energy is defined as the In the context of chemistry, energy is an attribute of a substance as a consequence of its atomic, molecular or aggregate structure.

\subsection{Exergy}

The German Engineer Rant first used the term "exergy" in 1956. Exergy is a property and is associated with the state of the system and the environment. The maximum amount of maximum work that can be done from the source for a engine.

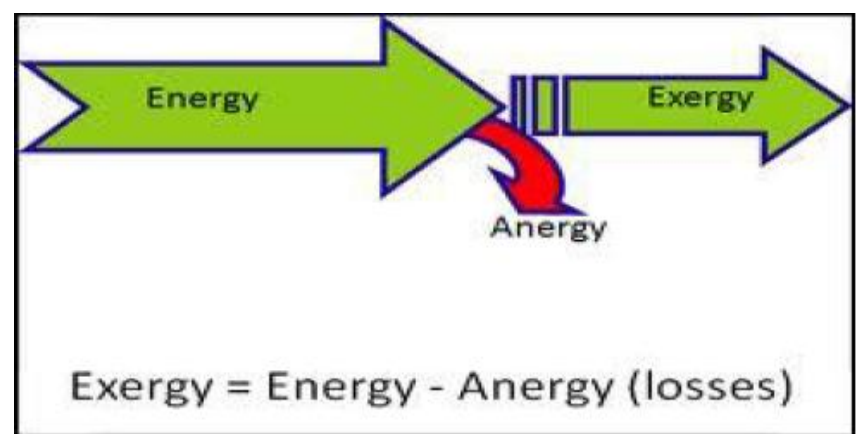

Fig 5: Exergy, Energy difference

\subsubsection{Need for Exergy}

$>$ In the last several decades, exergy analysis has begun to be used for system optimization.

$>$ By analyzing the exergy destroyed by each component in a process, we can see where we should be focusing our efforts to improve system efficiency.

$>$ It can also be used to compare components or systems to help make informed design decisions.

\subsection{Analysis Carried on Components}

$>$ Boiler

$>$ Economizer

$>$ Super heater

$>$ HPT

$>$ IPT

$>$ LPT
$>$ Condenser

$>$ Low pressure heater

$>$ High pressure heater

$>$ Ejectors

$>$ De-aerator

$>$ Booster pump etc.,

\section{At Boiler Inlet}

Pressure $\mathrm{P}=157.8$ bar, Temperature $\mathrm{T}=574 \mathrm{~K}$, mass flow rate, $\mathrm{m}=175 \mathrm{~kg} / \mathrm{s}$

From steam tables

Specific volume

$$
\mathrm{v}=0.001694 \frac{\mathrm{m} 3}{\mathrm{~kg}}
$$

Pressure difference

$$
\mathrm{dP}=157.8-157.8=0
$$

Temperature difference

$\mathrm{dT}=0 \mathrm{k}$

$$
\text { At } 574 \mathrm{k}, \mathrm{h}_{\mathrm{f}}=13450.4 \frac{\mathrm{kJ}}{\mathrm{kg}}
$$

Enthalpy in $\mathrm{Mw}, \mathrm{H}=1345.4 \times 175 \times 10^{-3}=235.445 \mathrm{Mw}$

At $574 \mathrm{k}, \mathrm{s}_{\mathrm{f}}=3.271$.

Entropy in $\mathrm{Mw} S=\mathrm{s}_{\mathrm{f}} \times \mathrm{mx} 10^{-3}$

$$
=3.271 \times 175 \times 10^{-3}=0.5724 \frac{M w}{K}
$$

\section{Boiler Outlet}

PRESSURE $\mathrm{P}=146.05 \mathrm{bar}$, TEMPERATURE $\mathrm{T}=613 \mathrm{~K}$,

Mass flow rate $=175 \frac{\mathrm{kg}}{\mathrm{s}}$.

Form steam tables

Enthalpy h=2626.2 $\frac{\mathrm{kJ}}{\mathrm{kg}} \quad$ Entropy $\mathrm{s}=5.3429 \frac{\mathrm{kJ}}{\mathrm{kg}-\mathrm{K}}$

Enthalpy in $\mathrm{Mw} \mathrm{H}=\mathrm{hxmx} 10^{-3}$

$\mathrm{H}=2626.2 \times 175 \times 10^{-3}=459.58 \mathrm{Mw}$

Enthalpy in $\mathrm{Mw} \mathrm{S}=\operatorname{sxm\times 10^{-3}}$

$=5.3429 \times 175 \times 10^{-3}=0.9349 \mathrm{Mw} / \mathrm{K}$ 


\section{Super Heater Inlet}

PRESSURE $\mathrm{P}=146.05$ bar, TEMPERATURE $\mathrm{T}=613 \mathrm{~K}$,

Mass flow rate mass flow rate $=177.78 \frac{\mathrm{kg}}{\mathrm{s}}$

From steam tables

Enthalpy $\mathrm{h}=2626.2 \frac{\mathrm{kJ}}{\mathrm{kg}} \quad$ Entropy s $=5.3429 \frac{\mathrm{kJ}}{\mathrm{Kg}-\mathrm{K}}$

Enthalpy in Mw

$\mathrm{H}=\mathrm{h} \times \mathrm{m} \times 10^{-3}$

$=2626.2 \times 177.78 \times 10^{-3}=466.88 \mathrm{Mw}$

Entropy in Mw

$\mathrm{S}=\mathrm{s} \times \mathrm{m} \times 10^{-3}$

$=5.3429 \times 177.78 \times 10^{-3}=0.9497 \frac{M w}{K}$

\section{Super Heater Outlet}

PRESSURE P = 146.05 bar, TEMPERATURE T = $540 \mathrm{c}$,

$$
\text { mass flow rate } \mathrm{m}=177.18 \frac{\mathrm{kg}}{\mathrm{s}}
$$

From steam tables

At 140.05 bar Enthalpy

$$
\begin{aligned}
& \mathrm{h}=3472.12+\frac{3482.62-3472.12}{10} \times(150-146.05) \quad \text { By } \\
& \text { interpolation }]=3476.26 \frac{\mathrm{kJ}}{\mathrm{kg}}
\end{aligned}
$$

Entropy values

\begin{tabular}{|l|l|l|l|}
\hline Pressure & $\mathbf{5 0 0}{ }^{\circ} \mathbf{c}$ & $\mathbf{6 0 0}{ }^{\circ} \mathbf{c}$ & $\mathbf{5 4 0}{ }^{\circ} \mathbf{c}$ \\
\hline $\mathbf{1 4 0}$ bar & 6.394 & 6.714 & 6.5872 \\
\hline $\mathbf{1 5 0}$ bar & 6.349 & 6.676 & 6.5452 \\
\hline
\end{tabular}

At 146.05 bar, interpolation values at $540^{\circ} \mathrm{c}$

$$
\begin{aligned}
& \text { Entropy } \mathrm{s}=6.5452+\frac{6.5872-6.5452}{10} \times(150-146.05)= \\
& 6.56179 \frac{\mathrm{kJ}}{\mathrm{kg}-\mathrm{K}}
\end{aligned}
$$

Enthalpy in $\mathrm{Mw} \mathrm{H}=\mathrm{hxmx} 10^{-3}$

$=3476.26 \times 177.78 \times 10-3=618.009 \mathrm{Mw}$
Entropy in $\mathrm{Mw} \mathrm{S}=\operatorname{sxmx} 10^{-3}$

$$
=6.56179 \times 177.78 \times 10^{-3}=1.1665 \frac{M w}{K}
$$

\section{EXERGY AND ENERGY CALCULATIONS ON THE COMPONENTS}

\subsection{Exergy Analysis Exergy Balance of High Pressure Turbine}

The exergy balance for the high pressure turbine is given by: $10 \rightarrow$ HPT inlet

$11 \rightarrow$ HPT ext

$14 \rightarrow$ HPT outlet

$\Psi=$ H-To.S

Work done by high pressure turbine,

$$
\begin{gathered}
\mathrm{W}_{\mathrm{HPT}}={ }^{\cdot} \mathrm{m}_{10}\left(\Psi_{10}-\Psi_{11}\right)+\left({ }^{\cdot} \mathrm{m}_{10}-\cdot \mathrm{m}_{11}\right)\left(\Psi_{11}-\Psi_{14}\right)- \\
\mathrm{T}_{\mathrm{o}} \times{ }^{\cdot} \mathrm{S}_{\mathrm{gen}}
\end{gathered}
$$

This gives:

$$
\begin{gathered}
\mathrm{T}_{0} \times \mathrm{S}_{\mathrm{gen}}={ }^{\cdot} \mathrm{m}_{10}\left(\Psi_{10}-\Psi_{11}\right)+\left({ }^{\cdot} \mathrm{m}_{10}-\cdot \mathrm{m}_{11}\right)\left(\Psi_{11}-\Psi_{14}\right)- \\
\mathrm{W}_{\mathrm{HPT}} \mathrm{m}_{10}\left(\Psi_{10}-\Psi_{11}\right)+\left(\underset{\text { input }}{\left.\mathrm{m}_{10}-\cdot \mathrm{m}_{11}\right)\left(\Psi_{11}-\Psi_{14}\right)=\text { Exergy }}\right. \\
\text { inpergy }
\end{gathered}
$$

And the entropy generation rate is:

$$
\cdot \mathrm{S}_{\mathrm{gen}}={ }^{\cdot} \mathrm{m}_{10}\left(\mathrm{~s}_{11}-\mathrm{s}_{10}\right)+\left(\mathrm{c}_{10}-{ }^{\cdot} \mathrm{m}_{11}\right)\left(\mathrm{s}_{14}-\mathrm{s}_{11}\right)
$$

Irreversibility destroyed = exergy loss is:

$$
\begin{aligned}
\cdot I \text { destroyed }=\text { To. } & \cdot \mathrm{S}_{\mathrm{ge}} \mathrm{n}=\mathrm{T}_{\mathrm{o}}\left[\mathrm{m}_{10}\left(\mathrm{~s}_{11}-\mathrm{s}_{10}\right)+\left(\cdot \mathrm{m}_{10}\right.\right. \\
& \left.\left.-\cdot \mathrm{m}_{11}\right)\left(\mathrm{~s}_{14}-\mathrm{s}_{11}\right)\right]
\end{aligned}
$$

The second law efficiency is:

$$
\begin{gathered}
\eta^{\mathrm{II}}{ }_{, \mathrm{HPT}}=1-\left(\mathrm{I}_{\text {destroyed }} \div \mathrm{m}_{10}\left(\Psi_{10}-\Psi_{11}\right)+\left(\cdot \mathrm{m}_{10}-\cdot \mathrm{m}_{11}\right)\left(\Psi_{11}\right.\right. \\
\left.\left.-\Psi_{14}\right)\right) \\
=\mathrm{W}_{\mathrm{HpT}} \div{ }^{\circ} \mathrm{m}_{10}\left(\Psi_{10}-\Psi_{11}\right)+\left(\cdot \mathrm{m}_{10}-\cdot \mathrm{m}_{11}\right)\left(\Psi_{11}-\Psi_{14}\right) \\
=1-(\text { Exergy loss/Exergy input }) \\
=\mathrm{W}_{\mathrm{HPT}} / \text { Exergy input }
\end{gathered}
$$

\section{Data:}

Exergy of high pressure turbine inlet

$$
\Psi_{10}=618.009-(301 \times 1.1665)=266.89 \mathrm{~kW}
$$

Exergy of high pressure turbine extraction

$$
\Psi_{11}=23.26-(301 \times 0.0533)=7.2167 \mathrm{MW}
$$

Exergy of high pressure turbine outlet

$$
\Psi_{14}=488.011-(301 \times 1.0520)=171.359 \mathrm{MW}
$$


$\mathrm{T}_{\mathrm{o}}=301 \mathrm{~K}$

By substituting in the above equations we get:

$$
\begin{gathered}
\text { Sgen }=177.78 \underset{(6.56179-6.4026)+(177.78-8.33)(6.529-}{6.4026)} \\
=28.3+21.418=49.718 \mathrm{~kW} / \mathrm{K}
\end{gathered}
$$

To ${ }^{` S g e n}=301 \times 49.718=14965.26 \mathrm{~kW}=14.96 \mathrm{MW}$

Work done by high pressure turbine

$\mathrm{W}_{\text {HPT }}=177(266.89-7.2167)+(177.78-8.33)(171.359$

$-7.216)-14965.26$

$$
=73978.749-14965.26=59013.489 \mathrm{~kW}
$$

Second law efficiency of high pressure turbine,

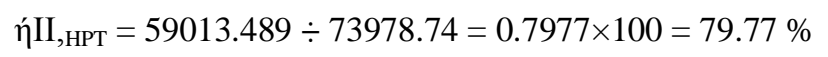

\section{3b. Energy Analysis Energy Balance of High}

\section{Pressure Turbine}

The energy balance for the high pressure turbine is given by $10 \rightarrow$ HPT inlet

$11 \rightarrow$ HPT ext

$14 \rightarrow$ HPT outlet

WHPT $={ }^{\cdot} \mathrm{m}_{10}\left(\mathrm{~h}_{10}-\mathrm{h}_{11}\right)+\left({ }^{\cdot} \mathrm{m}_{1} 0-{ }^{\cdot} \mathrm{m}_{11}\right)\left(\mathrm{h}_{11}-\mathrm{h}_{14}\right)-$ Energy loss

This gives :

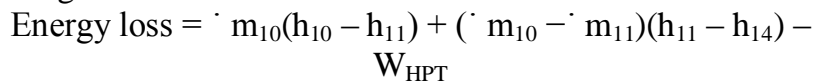

$$
\cdot \mathrm{m}_{10}\left(\mathrm{~h}_{10}-\mathrm{h}_{11}\right)+\left(\mathrm{m}_{10}-\cdot \mathrm{m}_{11}\right)\left(\mathrm{h}_{11}-\mathrm{h}_{14}\right)=\text { Energy input }
$$

Energy input $=177.78(3476.26-2983.41)+$ $(177.78-161.11)(2983.41-2793.28)=90788.33 \mathrm{~kW}$

$\mathrm{W}_{\mathrm{HPT}}=90788.33-$ Energy loss

$79.505 \times 1000=90788.33-$ Energy loss

\begin{tabular}{|c|c|c|}
\hline $\begin{array}{l}\text { Component } \\
\text { name }\end{array}$ & $\begin{array}{l}\text { First law } \\
\text { efficiency }(\eta I)\end{array}$ & $\begin{array}{l}\text { Second law } \\
\text { efficiency(ílI) }\end{array}$ \\
\hline HPT & $87.5 \%$ & $79.77 \%$ \\
\hline IPT & $96.8 \%$ & $85.99 \%$ \\
\hline LPT & $97.4 \%$ & $41.97 \%$ \\
\hline Superheater & $94.79 \%$ & $44.3 \%$ \\
\hline Condenser & $88.79 \%$ & $65.3 \%$ \\
\hline Boiler & $84.85 \%$ & $66.41 \%$ \\
\hline
\end{tabular}

Energy loss $=11283.33 \mathrm{~kW}$

The first law efficiency of high pressure turbine is:

$$
\begin{aligned}
& \eta \mathrm{I}, \mathrm{HPT}=1-\left(\text { Energy loss } \div\left({ }^{\cdot} \mathrm{m}_{10}\left(\mathrm{~h}_{10}-\mathrm{h}_{11}\right)+\left(\mathrm{m}_{10}\right.\right.\right. \\
& \left.\left.-\mathrm{m}_{11}\right)\left(\mathrm{~h}_{11}-\mathrm{h}_{14}\right)\right) \\
& =\mathrm{W}_{\mathrm{HPT}} \div\left({ }^{\cdot} \mathrm{m}_{10}\left(\mathrm{~h}_{10}-\mathrm{h}_{11}\right)+\left({ }^{\cdot} \mathrm{m}_{10}{ }^{\cdot} \mathrm{m}_{11}\right)\left(\mathrm{h}_{11}-\mathrm{h}_{14}\right)\right) \\
& =1-(\text { Energy loss/Energy input }) \\
& =\mathrm{W}_{\mathrm{HPT}} / \text { Energy input } \\
& =1-(11283.33 \div 90788.33)
\end{aligned}
$$

\section{RESULTS}

Table-1: Exergy, Energy Efficiency

\subsection{Exergy Vs Energy Efficiency Graph}

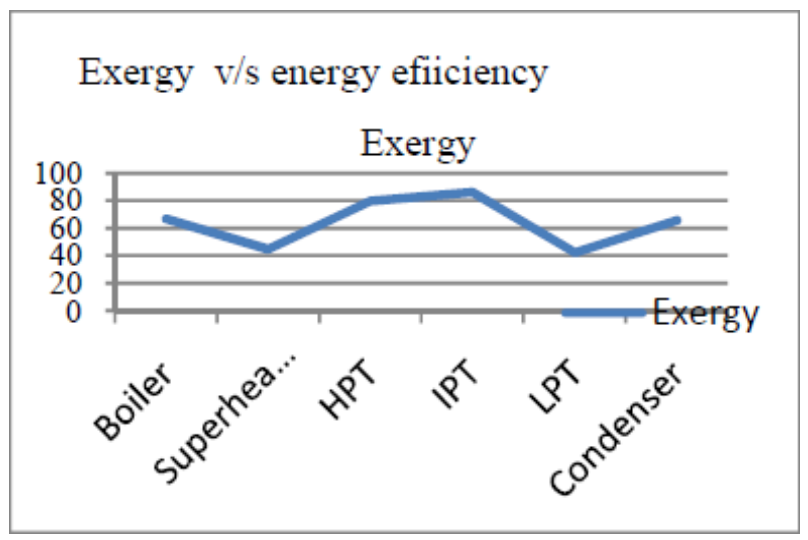

Graph-1: Exergy Vs Energy Efficiency

\section{CONCLUSION}

This project has presented the results of an exergy analysis performed on $210 \mathrm{MW}$ power plant. The analysis was applied on the unit with running load of $210 \mathrm{MW}$. Exergy destruction on the plant components are also presented and energy losses are discussed. The results of the exergy indicate that boiler produces highest exergy destruction of 72 MW. Comparing the 3 turbine stages, the results of the analysis indicate that HPT produces highest exergy destruction than IPT and LPT with further developments, graphs are plotted.

\section{REFERENCES}

[1] Ravi Prakash Kurkiya, Sharad Chaudhary, "International journal of scientific and energy research volume 3,2012."

[2] Vosough Amir, "2nd international conference on Mecanical,2012."

[3] P.K.Nag, "Engineering Thermodynamics, 4th edition, Mc.Graw Hill, 1995."

[4] Sam Cooper, Energy and exergy analysis. People.bath.ac.uk/en8c.

[5] A.GALOVIC, M.ZIVIC, M.kokanovic, " Analysis of exergy destruction of condenser-1987"

[6] A.Rashad, A.El Maihy, "13th International conference on Aerospaces and Aviation Technology."

$$
=0.875 \times 100=87.5 \%
$$

